УДК 316

$10.17213 / 2075-2067-2021-1-39-44$

\title{
ОБ АДМИНИСТРАТИВНОЙ СОСТОЯТЕЛЬНОСТИ ИНСТИТУТА СИТИ-МЕНЕДЖМЕНТА
}

\author{
(C) 2021 г. А. Н. Зеленый
}

\section{Юэнно-Российский государственный политехнический университет (НПИ) имени М. И. Платова, г. Новочеркасск, Россия}

Цель исследования. В данной работе представлена авторская концепциия оценки эффективности работы института сити-менеджмента под названием «административная состоятельность».

Методология исследования. Методологической основой работы является концепичия институциональной эволющии Д. Норта.

Результаты исследования. Административная состоятельность характеризуется субъективным признанием со стороны акторов муниципального управления способности достигнуть поставленной перед сити-менеджерами цели в виде повышения качества жизни населения муниципальных образований. По мнению автора, внедрение в российскую управленческую практику зарубежных моделей влечет за собой расхождение реальных и формальных практик, приводящее к снижению эффективности управленческих решений. Вмешательство власти в трудовой процесс и попьтки внедрить новые формы организачии труда зачастую сталкиваются с препятствиями, сформированными на уровне субъективного сопротивления инновациям, исходящими от основных акторов мунищипального управления.

Перспективы дальнейшего исследования. Выделены три эмпирических индикатора общественной состоятельности института сити-менеджмента (политико-управленческие ресурсы, хозяйственно-экономические ресурсы и риски как угроза недостижсения административной состоятельности института сити-менеджмента), позволяющие оиенить в различных муниципальных образованиях.

Ключевые слова: сити-менеджмент; неонституциональная теория; муниципальное управление; сити-менеджер; управленческая эффективность; инноваџии; местное самоуправление.

\section{ON THE ADMINISTRATIVE SOLVENCY OF THE INSTITUTION OF CITY-MANAGEMENT}

(C) 2021 A. N. Zeleny

\section{Platov South Russian State Polytechnic University (NPI), Novocherkassk, Russia}

The aim of the study. This paper presents the author's concept of assessing the effectiveness of the institution of city-management called «administrative solvency».

Research methodology. Methodological basis of the work is the concept of institutional evolution by $D$. North.

Research result. Administrative competence is characterized by subjective recognition on the part of municipal management actors of their ability to achieve the goal set for city-managers in 
the form of improving the quality of life in municipalities. According to the author, the introduction of foreign models into Russian managerial practice entails a divergence between real and formal practices, leading to a decrease in the effectiveness of managerial decisions. Interference of authorities in the labor process and attempts to introduce new forms of work organization often encounter obstacles formed at the level of subjective resistance to innovations coming from the main actors of municipal management.

Prospects of the study. Three empirical indicators of public consistency have been identified: political and managerial resources, economic and economic resources and risks as a threat of failure to achieve administrative consistency of the institution of city-management.

Key words: city-management; neo-institutional theory; municipal governance; city-manager; managerial efficiency; innovations; local self-government.

Введение. Современное Российское муниципальное управление находится в состоянии постоянных реформ и трансформаций, сопряженных с поиском оптимальной модели его функционирования. Этот поиск напрямую связан с устареванием советских методов хозяйствования и принятия управленческих решений, а также с необходимостью повышения профессионализма муниципальных служащих. Осознание федеральной властью этой необходимости позволяет сделать вывод о том, что современное российское муниципальное управление нуждается в модернизации, которая позволит ей оптимизировать свои управленческие практики и тем самым повысить эффективность своей деятельности, то есть достигнуть реальных результатов в повышении удовлетворенности потребителей муниципальных услуг.

Как показала практика, демократический способ организации публичной власти на местном уровне не оправдал ожиданий законодателя и не смог создать сильную муниципальную власть, способную поддерживать и развивать муниципальные пространства самостоятельно. Для решения этой проблемы в 2015 году Правительство внесло изменение в №131-Ф3 «Об общих принципах организации местного самоуправления в Российской Федерации» и предоставило возможность назначить главу администрации муниципального образования на основе контракта, заменив тем самым процедуру избрания мэров [1]. Подобный ход свидетельствует о том, что законодатель принес демократию в жертву управленческой эффективности. В отечественном научном дискурсе модель муници- пальной власти, при которой вступление главы администрации в должность происходит на основе заключаемого с ним контракта, называют «сити-менеджментом» по аналогии с «советно-управленческой системой», используемой в США [2]. Эта модель муниципального управления является заимствованной из совершенно другой социально-политической и институциональной реальности, следовательно, ее применение на практике сопряжено с большим количеством рисков социально-экономического и политического характера. По этой причине необходимо подвергнуть новую модель муниципального управления социологической экспертизе и выявить потенциал института сити-менеджмента в исполнении своей цели - повышение социально-экономических показателей развития муниципальных пространств.

Методология исследования. Методологической основой исследования является неоинституциональная теория, в частности, концепция институциональной эволюции Д. Норта, позволяющая интегрировать множество аспектов, важных для социологии управления: управленческий, юридический и социологический [3]. Они имеют высокую важность, так как объединяют не только правила вступления сити-менеджера в должность, но и ожидания акторов муниципальных пространств. Повышение качества жизни населения - основная цель муниципального управления, а институт сити-менеджмента призван повысить эффективность работы муниципальных служащих и глав местных администраций путем разделения политики 
и управления. Стоит отметить, что реальная практика работы российских институтов зачастую не совпадает с формальной, из чего следует, что результаты, поставленные перед институтом сити-менеджмента, могут быть не достигнуты из-за множества причин. Согласно неоинституциональной теории, структура формального института имеет три главных элемента: неформальные ограничения, формальные правила и механизмы принуждения. Это означает, что при изменении принципов работы на уровне формальных правил следует ожидать вступления в силу неформальных ограничений, среди которых можно назвать традиции, обычаи, социальные условности и прочие субъективные факторы, оказывающие влияние на управленческий труд в муниципальном управлении. Так как институт сити-менеджмента не является плодом планомерной институциональной эволюции конкретных муниципалитетов, а форсируется федеральной властью, то можно сказать, что вероятность субъективного сопротивления представителей местной власти будет очень высока. Объяснить это можно тем, что вмешательство в устоявшиеся формы организации труда всегда сопряжено с неформальным сопротивлением субъектов труда инновациям в рабочем процессе [4]. В контексте социологии управления это означает, что будет наблюдаться диссонанс реальных и формальных управленческих практик, что непосредственно скажется на эффективности управленческого труда сити-менеджеров. Необходимо сконцентрировать внимание на изучении потенциала института сити-менеджмента, преодолеть это сопротивление и перейти к продуцированию реальных результатов, направленных на улучшение качества жизни населения муниципальных пространств.

Отечественная научная традиция изучения института сити-менеджмента относительно молода, и дискурс, посвященный работе этого института, поляризован на сторонников и противников этой формы муниципального управления. Первые акцентируют внимание на антидемократичности сити-менеджмента, потере связей с местным населением, влекущей за собой снижение эффективности, а вторые указывают на положительные стороны разделения политики и управления, высокого управленческого потенциала наемных управленцев в сравнении с политически ангажированными мэрами [5]. Стоит отметить, что исследователи рассматривают сити-менеджмент в формате идеальной модели и не придают значения элементу неформального сопротивления столь непривычной для российской управленческой культуры формы организации муниципального управления. Мы считаем, что работа социальных институтов должна быть рассмотрена не только в формальной плоскости, но и в практической, так как в любой организации каждое нововведение сопряжено с оказываемым субъектами труда сопротивлением нововведениям. В случае муниципального управления это сопротивление неизбежно приведет к распространению имитационных практик, коррупции и усилению закрытого характера принятия решений. Неудавшаяся реформа влечет за собой высокие риски и требует комплексного научного осмысления, направленного на выявление сильных и слабых мест российской модели сити-менеджмента. В настоящий момент отсутствуют масштабные эмпирические исследования, посвященные тому, как институт сити-менеджмента функционирует на практике, а не в теории, поэтому мы предлагаем рассмотреть авторскую концепцию, позволяющую оценить, «состоялась» ли реформа сити-менеджмента и смогла ли она достигнуть поставленных перед ней целей.

Результаты исследования. Для выявления того, соответствуют ли реальные управленческие практики, реализуемые в рамках модели сити-менеджмента, формальным, мы представляем концепцию административной состоятельности. Под ней понимается субъективное признание со стороны акторов муниципального управления способности достигнуть поставленной перед сити-менеджерами цели в виде повышения качества жизни населения муниципальных образований. Она основывается на согласованном взаимодействии социальных акторов, которое в свою очередь свидетельствует о наличии устойчивых институциональных связей и отношений. Все вышеописанное призвано обеспечить условия, необходимые для решения поставленных перед муниципальными органами 
власти задач. Иными словами, состоятельность характеризуется соответствием реально достигнутых результатов поставленным целям, а административная состоятельность связана с готовностью сити-менеджеров, муниципальных служащих и других субъектов муниципального управления действовать согласно принципам, ориентированным на высокопрофессиональную работу с настоящими результатами.

Эмпирическими индикаторами административной состоятельности института ситименеджмента являются:

1) политико-управленческие ресурсы как инструмент достижения административной состоятельности института сити-менеджмента;

2) хозяйственно-экономические ресурсы как инструмент достижения административной состоятельности института сити-менеджмента;

3) риски как угроза недостижения административной состоятельности института сити-менеджмента.

Выбор этих индикаторов объясняется следующим образом: реальная и идеальная модели института сити-менеджмента не совпадают, следовательно, необходимо проанализировать, как сити-менеджеры используют полученные ресурсы и каковы риски их применения или неприменения.

Появление сити-менеджмента внесло изменения в устоявшиеся паттерны взаимодействия акторов муниципальных пространств, особенно сильно оно повлияло на субъекты муниципального управления, столкнувшиеся с новыми принципами организации своей работы и необходимостью подходить к ней более профессионально. При этом явно прослеживается несоответствие российской культуры управления и американской. Ситименеджмент хорошо показал себя в США, потому что демократическая форма организации публичной власти является функциональной и эффективной: потеря выборов мэра не исключает население городов из процесса управления городом, так как они контролируют деятельность местных депутатов, заинтересованных в эффективной работе [6]. В российской социальной реальности выборы на муниципальном уровне дискредитированы и не представляют никакого интереса для населения [7]. Это приводит к потере связи между властью и населением, следовательно, создает препятствия своевременной реализации функций муниципальной власти по удовлетворению потребностей жителей городов. Связь между населением и властью лежит не столько в политологической, сколько в социологической плоскости, так как она детерминирует продуктивность коммуникации муниципалитета и жителей городов. Эта коммуникация непосредственно влияет на внутренние трудовые процессы, имеющие место в муниципальной власти, так как она определяет степень «отчетности» власти перед населением. При потере этой коммуникации утрачивается и вышеописанная связь с горожанами, представители местной власти перестают понимать, куда следует направлять те или иные муниципальные ресурсы, что приводит к снижению продуктивности работы всей местной инфраструктуры.

Неолиберальный подход к менеджменту, подразумевающий разделение политики и управления, характерен для западных демократических систем организации публичной власти, которые могут эффективно функционировать [8]. Российская модель организации властных отношений традиционно выстраивается на принципах единоначалия, вертикального подчинения и патернализма, что совершенно не совпадает с описанным выше зарубежным подходом. Это позволяет сказать, что несовпадение форм организации деятельности на уровне культуры управления повлечет за собой серьезную «отдачу» на уровне неформальных ограничений. В связи с этим мы усматриваем дальнейшие перспективы исследования института ситименеджмента посредством эмпирических социологических процедур, направленных на выявление совпадения реальных управленческих практик российских сити-менеджеров с заданными законодателем на формальном уровне. Реализовать это возможно посредством экспертных опросов, глубинных интервью и фокус-групп с представителями местных администраций, муниципальными служащими, сити-менеджерами и заместителями глав администраций.

Заключение. Резюмируя все вышесказанное, можно прийти к выводу о том, что институт сити-менеджмента является импор- 
тированной из западной институциональной среды формой муниципального управления, внедрение которой несет за собой множество рисков. Они основываются на несовпадении управленческих культур США и России, следовательно, высока степень инициации неформальных ограничений, препятствующих полноценной работе нового института. Их выявление напрямую связано с социологической экспертизой института сити-менеджмента и выявления потенциала сити-менеджеров достигнуть реальных результатов по поставленным перед ними целям. Для этого требуется оценить институт сити-менеджмента с позиций его административной состоятельности - субъективного признания со стороны акторов муниципального управления способности достигнуть поставленных перед сити-менеджерами целей, связанных с повышением профессионализма муниципальных управленцев. Таким образом, выявление сильных и слабых сторон модели сити-менеджмента позволит определить основные направления оптимизации российского сити-менеджмента и повысить вероятность успешного достижения поставленных перед ним целей.

\section{Литература}

1. Федеральный закон от 06.10.2003 г. №131-Ф3 (ред. от 29.12.2020 г.) «Об общих принципах организации местного самоуправления в Российской Федерации».

2. Дятлов А.В., Ковалев В.В., Понамарев А.Б. Исторические предпосылки, содержание и опыт реализации института ситименеджмента в США // Научный результат. Серия: социология и управление. - 2020. T. 6 (1). - C. 80-90.

3. North Institutions, institutional change and economic performance. - Cambridge University Press, 1990 . - $152 \mathrm{p}$.

4. Троицкая A.A. Институциональные препятствия развитию инновационной активности российских предприятий // Управление экономическими системами. - 2014. №12 (72). - С. 8-18.

5. Ковалев В. В., Чигрин В.А. Политикоадминистративные основания для модели «сити-менеджмента» в системе российского муниципального управления // Ученые за- писки Крымского федерального университета имени В.И. Вернадского. Социология. Педагогика. Психология. - 2018. - Т. 4. №2. - С. 30-38.

6. Дятлов А. В., Чигрин В.А. Социокультурные основания для модели «сити-менеджмента» в системе российского муниципального управления // Ученые записки Крымского федерального университета имени В.И. Вернадского. Социология. Педагогика. Психология. - 2018. - Т. 4. - №1. - С. 3-9.

7. Постников А.Е. Эволюция института выборов в России в контексте реализации конституционных принципов // Журнал российского права. - 2019. - №5. - С. 12-24.

8. Русакова О.Ф., Хмелинин А.А. Глобальная стратегия неолиберальных трансформаций: критический анализ // ДискурсПи. - 2015. - №2. - C. 10-12.

\section{References}

1. Federal'nyj zakon ot 06.10.2003 g. №131 FZ (red. ot 29.12.2020 g.) «Ob obshhih principah organizacii mestnogo samoupravlenija $\mathrm{v}$ Rossijskoj Federacii» [Federal Law №131-FZ of 06.10 .2003 (as amended on 29.12.2020) «On the General principles of the organization of Local Self-Government in the Russian Federation»)].

2. Djatlov A. V., Kovalev V.V., Ponamarev $A$. $B$. Istoricheskie predposylki, soderzhanie i opyt realizacii instituta siti-menedzhmenta $\mathrm{v}$ SShA [Historical prerequisites, content and experience of the implementation of the Institute of City Management in the USA] // Nauchnyj rezul'tat. Serija: sociologija i upravlenie [Scientific result. Series: sociology and Management]. — 2020. — Vol. 6 (1). — Pp. 80-90.

3. North Institutions, institutional change and economic performance. - Cambridge University Press, 1990. - $152 \mathrm{p}$.

4. Troickaja A.A. Institucional'nye prepjatstvija razvitiju innovacionnoj aktivnosti rossijskih predprijatij [Institutional obstacles to the development of innovative activity of Russian enterprises] // Upravlenie jekonomicheskimi sistemami [Management of Economic Systems]. - 2014. — №12 (72). - Pp. 8-18.

5. Kovalev V.V., Chigrin V.A. Politiko-administrativnye osnovanija dlja modeli «siti-menedzhmenta» V sisteme rossijskogo municipal'nogo upravlenija [Political and administrative bases for 
the model of «city-management» in the system of Russian municipal management] // Uchenye zapiski Krymskogo federal'nogo universiteta imeni V.I. Vernadskogo. Sociologija. Pedagogika. Psihologija [Scientific notes of the Crimean Federal University named after V.I. Vernadsky. Sociology. Pedagogy. Psychology]. — 2018. - Vol. 4. №2. - Pp. 30-38.

6.Djatlov A. V., Chigrin V.A. Sociokul'turnye osnovanija dlja modeli «siti-menedzhmenta» v sisteme rossijskogo municipal'nogo upravlenija [Sociocultural foundations for the model of «city management» in the system of Russian municipal management] // Uchenye zapiski Krymskogo federal'nogo universiteta imeni V.I. Vernadskogo. Sociologija. Pedagogika. Psihologija
[Scientific notes of the Crimean Federal University named after V.I. Vernadsky. Sociology. Pedagogy. Psychology]. — 2018. — Vol. 4. №1. - Pp. 3-9.

7. Postnikov A.E. Jevoljucija instituta vyborov v Rossii v kontekste realizacii konstitucionnyh principov [Evolution of the Institute of elections in Russia in the context of the implementation of constitutional principles] // Zhurnal rossijskogo prava [Journal of Russian Law]. 2019. - №5. - Pp. 12-24.

8. Rusakova O.F., Hmelinin A.A. Global'naja strategija neoliberal'nyh transformacij: kriticheskij analiz [Global strategy of neoliberal transformations: a critical analysis] // DiskursPi. - 2015. - №2. - Pp. 10-12.

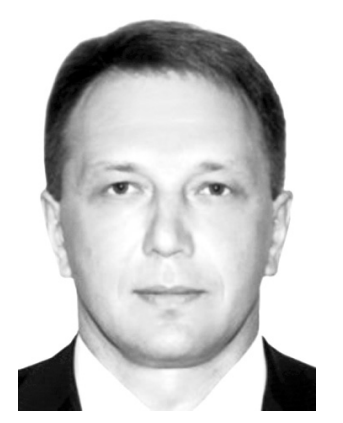

Зеленый Андрей Николаевич - аспирант Южно-Российского государственного политехнического университета (НПИ) имени М.И. Платова.

Zeleny Andrey Nickolaevich - Postgraduate student, Platov South Russian State Polytechnic University (NPI).

346428, г. Новочеркасск, ул. Просвещения, 132 132 Prosveshcheniya st., 346428, Novocherkassk, Russia E-mail: green1969@mail.ru 